\title{
Advanced composite structure combining Ultra high performance concrete with normal reinforced concrete
}

\author{
Xiangguo $\mathrm{Wu}^{1,2}$ \\ ${ }^{1}$ Key Lab of Structures Dynamic Behavior and Control of the Ministry of Education and School of Civil Engineering, Harbin Institute of \\ Technology, Harbin 150090, China \\ ${ }^{2}$ Key Lab of Smart Prevention and Mitigation of Civil Engineering Disasters of the Ministry of Industry and Information Technology, \\ Harbin Institute of Technology, Harbin 150090, China
}

\begin{abstract}
Ultra high performance concrete (UHPC), one of the newest cementitious composites, demonstrates superior ductility with high strength and durability, which has gained the attention of researchers and engineers since it was successfully developed. Considering its superior ductility and durability, UHPC is a good alternative material for forming a advanced composite structure with normal reinforced concrete $(\mathrm{RC})$ or prestressed concrete. The material properties are critical for its application in composite structures, so in this chapter, material properties of UHPC, such as constitute raw materials, mechanical properties, durability and several constitutive relations from several standards are firstly introduced. The basic concepts of advanced UHPC-RC composite structures, such as UHPC-RC composite beam, composite column, composite wall, etc, are introduced finally.
\end{abstract}

\section{Material properties of UHPC}

UHPC can be developed based on the improvement of high strength cementitious material or high performance cementitious material by the use of particle packing model. Developing of optimum packing density and discovery of suitable superplasticizer and micro filler like silica fume helpes the cementitious composites gain high strength and good workability with low water-cement ratio[1].

\subsection{Raw materials}

The constituent raw materials of UHPC include Portland cement, silica fume (SF), quartz powder, quartz sand, superplasticizer, and fibers. The following sections will discuss the raw materials of UHPC briefly. The common cementitious components include Portland cement, silica fume (SF)[2]. In most cases, CEM I 52.5 is used, however, there are also promising alternatives with other cement types such as CEM III/B [3]. Silica fume (SF): SF is an industrial byproduct of ferro-silicium alloy production and has a typical diameter of 0.2. In 1993, Richard et al. [3] proposed that silica fume content should be around $25 \%$ of Portland cement. Chan [4] concluded that the optimal silica fume content was between $20 \%$ and $30 \%$ in terms of the bond characteristics. Actually, the optimum silica fume content was highly dependent on $w / c$, and a lower $w / c$ required lower silica fume content [5]. Quartz sand is normally used as aggregate in UHPC, since it has high hardness and provides good pasteaggregate interfaces. Superplasticizers are essential for the processing (workability) of UHPC with their low water-content. In general, superplasticizers of the third generation - polycarboxylates and polycarboxylatethers are used, since they are highly efficient and have no efficiency threshold for low w/c-ratios [6]. Steel fibers and organic fibers, such as carbon fibers, glass fibers, PP fibers, are used in UHPC [7-9]. The different fibers work at the material scale to increase the tensile strength and at the structural scale to increase resistance and deformation capacity. Typically, UHPC have fiber content of $2 \%$.

\subsection{Mechanical properties}

\subsubsection{Compressive behavior}

As UHPC has different ingredients from typical concrete with steel fibers and no coarse aggregate, it may show different behavior. Based on the research by Aaleti, Petersen[10], the 28-days compressive strength of UHPC depends on the curing process type. It is also affected by specimen size, steel fibers and loading rate. Effect of specimen size and shape: The specimen size has a significant influence on the measured compressive strength of UHPC. For instance, Skazlic et al. [11] observed $21 \%$ increase in cylinder compressive strength for a specimen size of $70 \mathrm{~mm} \times 140 \mathrm{~mm}$ compared to that of $100 \mathrm{~mm} \times 200 \mathrm{~mm}$. This is likely due to the higher probability of encountering larger size flaws in larger specimens [12]. Moreover, it was observed that cube specimens exhibited higher strength compared to that of cylindrical specimens due to the well-known confinement effect of the testing machine platens [13]. 
Effect of steel fibers:The compressive strength is weakly influenced by the addition of high dosages of steel fibers [14]. A slight increase in compressive strength due to fiber addition can be observed if proper thermal treatment is applied. This mainly depends on the type of fibers and their dosage. For example, approximately $30 \%$ increase in compressive strength was observed with the addition of $2.5 \%$ by mixture volume of steel fibers when specimens were subjected to thermal treatment [15]. This increase in UHPC compressive strength was attributed to the enhanced tolerance of lateral strains owing to steel fiber addition [16]. Effect of loading rate: According to AFGC-SETRA [17] guidelines, a loading rate ranging between 0.24 and $1.7 \mathrm{MPa} / \mathrm{s}$ effected the UHPC compressive strength by less than $4 \%$.

\subsubsection{Tensile behavior}

The tensile strength of UHPC is much higher than that of normal concrete. The tensile strength can be determined by flexural test, direct tensile test and splitting tensile test.

Effect of fiber: It was observed that fibers significantly affect the UHPC flexural properties [16]. The flexural strength of UHPC increased linearly with increased fiber dosage [18]. Besides, it was observed that the flexural capacity of UHPC was also dependent on the aspect ratio of fibers. For instance, UHPC mixtures incorporating higher aspect ratio fibers had increased flexural capacity compared to that of those with lower aspect ratio fibers [19]. Furthermore, the fiber orientation also has an important effect on the tensile strength.

Size effect: Wille and Parra-Montesinos [20] investigated the size effect on the flexural strength by performing three- and four-point bending tests. From these test results, they concluded that the size effect on the flexural strength of UHPC is negligible and follows the yield criterion because of its high ductility. This is consistent with the findings of Spasojavic et al. [21], who stated that the size effect in thin flexural members made of UHPC was negligible. However, Reineck and Greiner [22] and Frettlohr et al. [23] mentioned that the axial tensile strengths of UHPC distinctively decreased with increasing the specimen size (an obvious size effect).

\subsection{Durability}

\subsubsection{Porosity}

UHPC exhibits high durability properties due to a substantial decrease in the number and size of pores. The average pore size in UHPC was found to be less than 5 $\mathrm{nm}$ and the pore volume ranges from $1 \%$ to $2 \%$ of the total volume [24]. It was observed that the total porosity is mainly dependent on the heat treatment and water-tobinder. For instance, the total porosity decreased from $8.4 \%$ to $1.5 \%$ due to UHPC heat treatment [25]. Roux et al.[26] observed 50\% reduction in porosity upon the application of pressure during the initial setting time.
UHPC shows very low water absorption capacity, which is approximately 10 and 60 times lesser than that of HPC and NSC, respectively [27]. The water permeability coefficient of UHPC was reported to be about 0.0005 , which is very low compared to that of the NSC (around 0.0015) [28]. Likewise, UHPC showed very low permeability to oxygen as compared to that of NSC and HPC. For instance, the UHPC permeability to oxygen is less than $1 \times 10-19 \mathrm{~m}^{2}$, which is around 10 and 100 times lesser than that of HPC and NSC, respectively [24]..

\subsubsection{Chloride penetration}

It was observed that the addition of steel fibers in UHPC did not cause any electrical short circuiting during the rapid chloride penetrability test due to their shorter length and randomly discontinuous distribution [12]. It was also found that the total charges passed through thermally treated UHPC specimens (35mm thick) was 22 Coulombs, which is very low compared to that of HPC (e.g. 216 Coulombs) and NSC (e.g. 1736 Coulombs) [14].

No freeze-thaw degradation was observed for UHPC specimens after 800 of freezing-thawing cycles, which was attributed to less interconnected pores [29]. The study conducted by Vernet [24] found no considerable deterioration on UHPC after 500 freezing thawing cycles along with 4500 wetting-drying cycles. Furthermore, it was observed that the addition of steel fibers appeared to decrease the internal material degradation due to freezethaw cycling [30].

\subsection{Model parameters (Constitutive model)}

Based on the experimental results, some constitutive model has been developed for designing, and some countries have issued standard or recommendations, such as JSCE 2008[31], NF P18-470(2016)[32], and so on. The compressive and tensile constitutive law from JSCE 2008 and NF P18-470(2016) are briefly introduced.

\subsubsection{Compressive stress-strain curve for UHPC}

From Figure 1, it can be seen that compressive stress increased linearly with the increment of strain. After the compressive stress is up to its compressive strength, it still remains compressive strength during the strain is between the peak strain and ultimate strain. When the strain reaches the ultimate strain, the compressive stress will be zero.

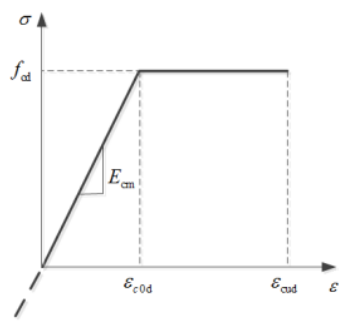

(a)NF P18-470(2016)

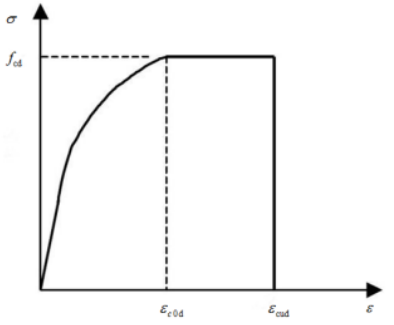

(b) JSCE( 2008)
Fig. 1. The compressive stress-strain curve

\subsubsection{Permeability}


The detailing of compressive law can be found from JSCE 2008 and NF P18-470（2016）.

\subsubsection{Tensile stress-strain curve for UHPC}

For tensile stress-strain curve from NF P18-470 (2016), it is different for thin and thick members. Here, Figure 2 (a) is the design tensile constitutive law for thin members from NF P18-470 (2016), which is similar with that from JSCE( 2008), however, the value of characteristic points, for example, $f_{t d}$ from different standard is not the same. In NF P18-470(2016), $f_{t d}=f_{c t f k} / K$, where $K$ is the orientation factor; in $\operatorname{JSCE}(2008), f_{t d}=f_{t y k} / \gamma_{c}$, where $\gamma_{c}$ is the material safety factor.

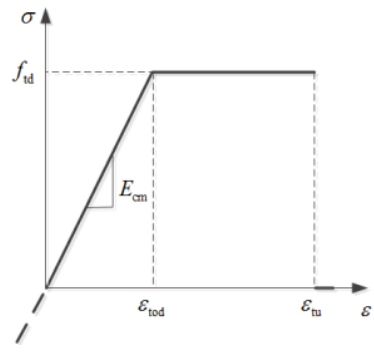

(a)NF P18-470(2016)

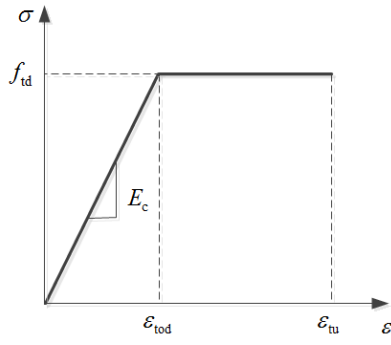

(b) JSCE( 2008)
Fig. 2. The tensile stress-strain curve

\section{UHPC-RC composite structures}

\subsection{Basic concept of UHPC-RC composite beam}

Permanent formwork, also called disassembly-free formwork or disposable formwork, it means no formwork removal work is required after casting of concrete [33]. After casting of concrete, the formwork work together with cast-in-place concrete. This semi-prefabricated concrete structure can effectively reduce the dead weight of fabricated components, which is convenient to transport and lifting. It also simplifies the construction process of cast-in-place reinforced concrete structures, greatly reduces the assembly and disassembly of the formwork, improves working conditions, save the work of assembling and disassembling of the formwork, accelerated construction progress, promote the industrialization of the building, shorten construction period and increase construction efficiency [34]. Permanent formwork has a wide range of application prospects.

UHPC, as the latest generation of high performance concrete, has excellent mechanical properties and extremely high durability $[35,36]$. Using UHPC as a prefabricated unit, combined with cast-in-place reinforced concrete $(\mathrm{RC})$ into a new type of composite structure, is a research direction. The most significant feature of this kind of composite structure is that the durability and fire resistance of the structure are significantly improved [37]. The UHPC-RC composite beam is a new type of semi-prefabricated assembly beam that uses UHPC as a prefabricated unit and is combined with cast-in-place reinforced concrete (RC). UHPC is often used as a prefabricated permanent formwork. The UHPC permanent formwork for UHPC-RC composite beams is prefabricated at the factory and then casting of ordinary concrete at the construction field.

An example section of UHPC-RC composite beams is shown in Figure 3. As shown in the Figure 3, the outer layer of beam section is U-shape UHPC permanent formwork, the inner layer is core concrete. Due to the superior mechanical properties of UHPC, the thickness of prefabricated U shape shell can be greatly reduced, the weight of semi-prefabricated components can be effectively reduced and is convenient to transport and construct. According to the actual situation, the longitudinal reinforcement and stirrups can be place inside the UHPC permanent formwork or inside the core concrete. In order to improve the bonding performance between UHPC formwork and core concrete, the inner surface of UHPC formwork should be roughed to improve the roughness of contact surface, or connect UHPC formwork and core concrete by bolt connector.

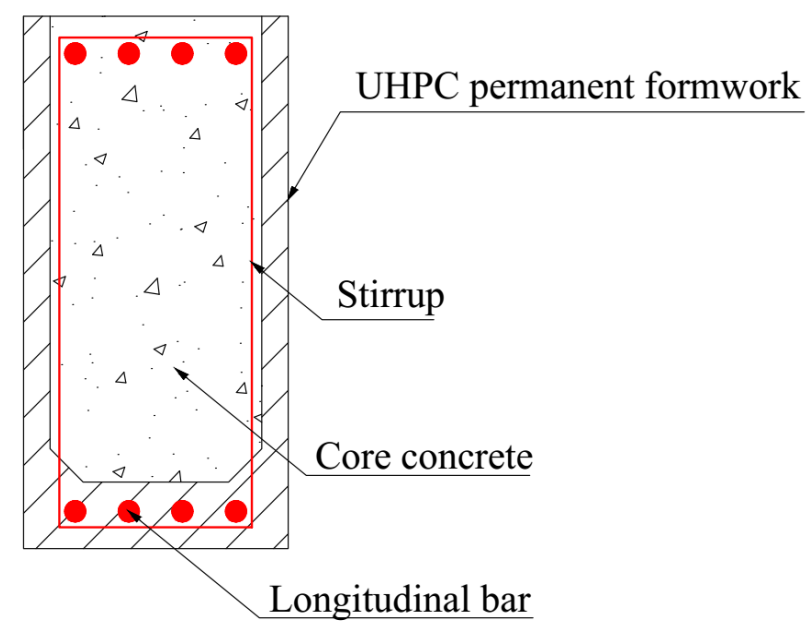

Fig. 3. UHPC-RC composite beam

According to previous studies [38-40], since UHPC has superior tensile strength and compressive strength, precast UHPC element has a significant effect on the bending capacity, shear capacity and torsion capacity of composite beam. Second, because UHPC has strong durability, it can greatly improve the durability of the composite beam. Third, precast UHPC formwork can significantly improve the stiffness of composite beam, which can reduce mid-span deflection of composite beam.

\subsection{UHPC-RC composite column}

To improve brittle damage of normal concrete, concrete column is often confined by stirrup or steel tube (Concrete-filled steel tube) in the past decades. However, researches and engineering has revealed that there are some drawbacks, for example, it is difficult to compact when normal concrete is poured into steel tube in situ for concrete-filled steel tube, and the need to take measures to deal with the problem of corrosion and fire resistance of steel tube. 


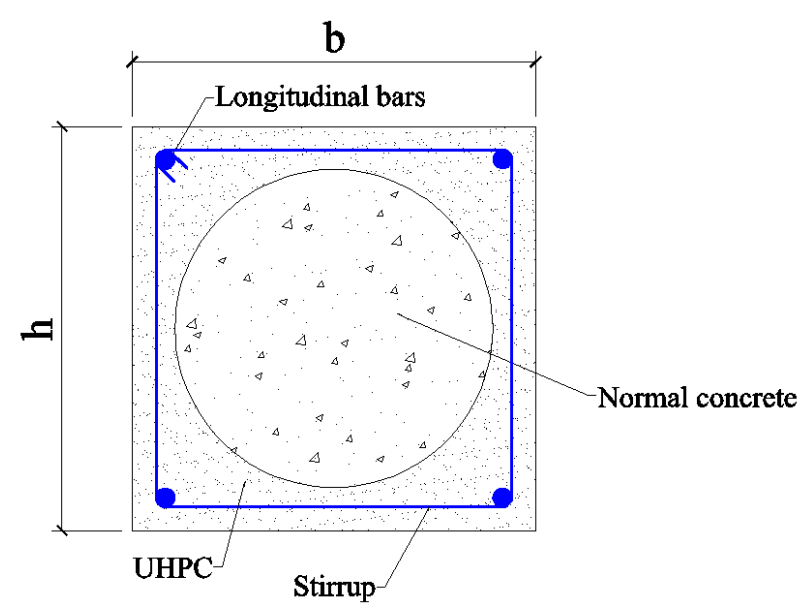

Fig. 4. UHPC-RC composite column

Considering the superior ductility with high strength and durability, UHPC is a good alternative construction material to form UHPC-RC composite column shown in Figure 4, which is composed by precast UHPC as a permanent form and cast-in-situ normal concrete core.

Compared to conventional precast concrete column, handling load is significantly reduced because of an empty core, so under the same handling load, the length of precast UHPC can be extended, and the joint of UHPC-RC column can be reduced. As the joint is often weak area for the assembly structure, the behaviors of UHPC-RC column can be improved by the reduction of cast-in-situ joint. Besides, if the steel bars are embedded in precast UHPC, it will be a better quality of steel bars when it is fixed in factory.

For the better confinement effect, the bond between the concrete core and the precast UHPC tube is necessary throughout the length of the column, which is critical for composite column to work together. To achieve this, the threaded bars were embedded through the columns as shear connectors [41]. The uniaxial compression behaviors of UHPC-RC composite column with $1.5 \%$ and $2 \%$ fiber volume $\left(V_{f}\right)$ along with $1.26 \%$ and $2.52 \%$ transverse steel ratio for core concrete were studied by Issa Brown Mpalla[41]. The wire mesh improves the cracking strength of the structural column. In this experiment, the wire meshed column was $13.8 \%$ higher in cracking strength compared to the column without a wire mesh. Besides, the axial loading-carrying capacity of UHPC-RC composite column was higher than the sum of that of hollow UHPC tube and internal concrete, indicting this composite system realizes the superposition effect [42].

\subsection{Laminated Plate Shear Wall of UHPC}

The laminated plate shear wall is comprised by two layers of the precast concrete wall panels and the cast-insitu concrete in the middle, which is a kind of new shear wall structure. The two layers of the precast concrete wall panels are connected by the lattice reinforcement, when installed at the position concrete can be poured between them as shown in Figure 5.

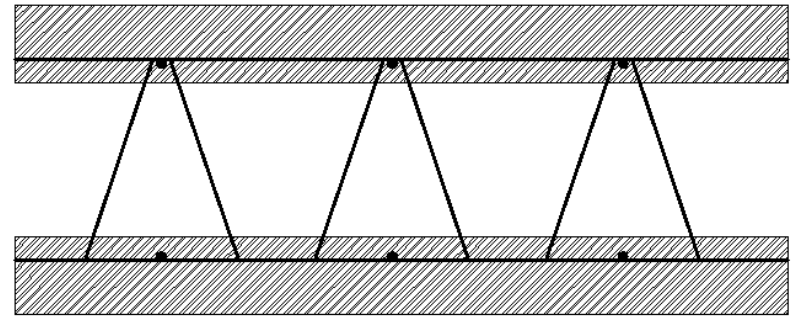

Fig. 5. laminated plate shear wall

Many researchers are considering using the UHPC as the precast concrete wall panels to enhance the behavior and load carrying capacity of the laminated plate shear wall. The superiority of the UHPC is its high compressive and tensile strength and its excellent rheological properties. The use of the UHPC can improve the intensity, rigidity and ductility of the precast concrete wall panels so that it can be a great idea in building high buildings.

\subsection{UHPC-EPS-RC sandwich panel}

UHPC-EPS-RC sandwich panels are composite structures made of two layers of concrete with a lightweight thermally insulating core in between. Connectors are usually applied inside to bond these layers together as an integrated unit. This kind of panel makes use of a low density core material, the high tensile and compressive strength of UHPC and RC slabs and the shear capacity of composite connectors to obtain high strength weight ratios. The exterior layer to external environment is made of UHPC. Middle layer is an insulating core of Expanded Polystyrene (EPS), a kind of honeycomb and rigid polystyrene foam with high thermal and fire resistance properties and low permeability. Interior layer is made of normal reinforced concrete and it works like normal structural panels.

The panels can be designed to withstand both in-plane and out-of-plane forces. Besides its self-weight, the panel can resist a certain degree of axial compressive load or bias compressive load. The panels act much like an Ibeam where the concrete skin behaves as flanges to resist bending stresses and the middle core correlates with the web of the I-beam in resisting shear only. To provide resistance against lateral loads, like those generated by wind or blast pressures, sandwich wall panels behave in a composite manner. The structural efficiency of the panel relies mostly on the degree of composite action between the exterior UHPC and interior RC section. A full composite action is achieved when the panel behaves as one unit in a way similar to a solid slab. In partially composite panels, local bending would occur in each of the concrete section.

Shear ties are utilized to achieve a level of composite action between the interior and exterior concrete layers. A series of high strength composite connectors are designed to increase shear strength between layers and solve heat bridge problem.

\section{Summary}


Considering the superior ductility and durability of UHPC, UHPC-RC composite structure will be a good method to improve the behavior of RC structure.

The part of material properties of UHPC firstly introduces the constituent raw materials of UHPC, such as the cement, SF, fibers and superplasticizer. After that, the compressive and tensile properties and the main effects on its compressive and tensile strength are revealed. The durability of UHPC is excellent in term of porosity, permeability, chloride penetration and freezethaw durability compared to normal concrete and HSC. Finally, the common constitutive model of compressive and tensile properties for UHPC from JSCE 2008 and NF P18-470(2016) are introduced.

The part of UHPC-RC composite structures firstly introduces the concept of this composite structure, including UHPC-RC composite beam, composite column, composite shear wall, and UHPC-EPS-RC sandwich panel. Prospective application are of UHPC-RC can be any civil engineering structure including urban infrastructure and building under sever conditions.

\section{Acknowledgments}

The authors would like to thank the National Natural Science Foundation of China (51678196), the NSFCNRF joint project(51811540401), and the Heilongjiang Province Natural Science Fund (E2015014) for providing funding to this project for the supporting the authors' work described herein.

\section{References}

1. J.H. Lee, Shear Strength of Ultra-High Performance Fiber Reinforced Concrete I-shaped Beams [thesis]. Seoul: Seoul National University(2017)

2. I. Talebinejad, S.A. Bassam, A. Iranmanesh, M. Shekarchizadeh, Proceedings of the International Symposium on Ultra High Performance Concrete, pp, 133-141(2004)

3. P. Richard, M. Cheyrezy, Cem. Concr. Res, 25, 15011511(1995)

4. Y.W. Chan, S.H. Chu, Cem. Concr. Res, 34, 11671172(2004)

5. V.T.A. Van, H.M. Ludwig, Proceedings of the 3rd International Symposium on UHPC and Nanotechnology for High Performance Construction Materials(2012)

6. K. Holschemacher, F. Dehn, König G, Holschemacher $K$, Dehn F, editors. Ultrahochfester Beton, Innovationen im Bauwesen Beiträge aus Praxis und Wissenschaft, p, 112(2003)

7. A.E. Naaman, Proceedings of the JCI international Workshop on Ductile Fiber Reinforced Cementitious Composites (DFRCC)-Application and Evaluation (DFRCC-02), p, 33-57(2002)

8. P. Rossi, P. Acker, Y. Malier, Mater Struct, 20, 436439(1987)

9. P. Rossi, Proceedings of the International Conference, p, 17-29(2002)
10. S. Aaleti, B. Petersen, S. Sritharan, Design Guide for Precast UHPC Waffle Deck Panel System Including Connections(2013)

11.M. Skazlic, D. Bjegovic, M. Serdar, Proceedings of the 2nd International Symposium on Ultra High Performance Concrete, p, 295-301(2008)

12. B.A. Graybeal, FHWA-HRT-06-103, p, 176(2006)

13. S. Kazemi, A. Lubell, ACI Mater. J. 109, 675684(2012)

14. M. Schmidt, E. Fehling, T. Teichmann, K. Bunje, R. Bornemann, Concr Precasting Plant Tech, 69, 1629(2003)

15. M. Soutsos, S. Millard, K. Karaiskos, Mater Struct, 549-560(2005)

16. S. Kazemi, A. Lubell, ACI Mater. J. 109, 675684(2012)

17. AFGC-SETRA. Ultra-high performance fibrereinforced concretes recommendations provisoiresinterim recommendations, p, 98(2002)

18. S. Kang, Y. Lee, Y. Park, J. Kim, Compos Struct, 92, 61-71(2010)

19.Y. Ye, S. Hu, B. Daio, S. Yang, Z. Liu, ASCE CICTP, 3017-3028(2012)

20. K. Wille, G.J. Parra-Montesinos, ACI Mater J. 3, 379-388(2012)

21. A. Spasojavic, D. ReDaelli, M. Fernandez Ruiz, A. Muttoni, Proceedings of the 2nd International Symposium on Ultra High Performance Concrete, p, 303-310(2008)

22. K.H. Reineck, S. Greiner, Advances in Construction Materials, 211-218(2007)

23. B. Frettlohr, K.H. Reineck, H.W. Reinhardt, Proceedings of High Performance Fiber Reinforced Cement Composites 6, p, 365-372(2012)

24. P. Vernet, Mater Res Soc, 29, 324-327(2004)

25. A. Cwirzen, Advances in Cement Research, 19, 2533(2007)

26. N. Roux, C. Andrade, M. Sanjuan, J Mater Civil Eng, 8, 1-6(1996)

27. M. Schmidt, E. Fehling, Proceedings of the 7th International Symposium on Utilization of High Strength High Performance Concrete, p, 51-77(2005)

28. D. Wang, C. Shi, Z. Wu, et al, Constr Build Mater, 96, 368-377(2015)

29. L. Juanhong, S. Shaomin, W. Lin, J Wuhan Univ Technol, 24, 506-509(2009)

30. A. Cwirzen, V. Penttala, K. Cwirzen, Proceedings of the 2nd International Symposium on Ultra High Performance Concrete, p, 221-230(2008)

31. JSCE. Recommendation for Design and Construction of High Performance Fiber Reinforced Cement Composites with Multiple Fine Cracks (HPFRCC), Concrete Engineering Series 82(2008)

32. NF P18-470 Concrete - Ultra-high performance fibre-reinforced concrete - Specifications, performance, production and conformity (2016)

33. J.S. Zhang, Y. Zeng, Y. Wang, Journal of Shenyang architecture and civil engineer institute, 15, 71-72(1999) 34. Y. Xun, Y.H. Xu, H.Y.Yin, Concrete, 1, 25-28(2016) 35. B.A. Graybeal, Federal Highway Administration(2011) 
36. Wu XG, Han S, Xu SL, Acta Mater Compos Sin, 25, $129-134(2018)$

37. X.G. Wu, X.C. Zhang, Y. Lin, Proceeding of China National Silicate Academy Concrete and Cement Products Branch National High Performance Concrete Symposium 21-23, p, 44-50(2015)

38. Y. Lin, Flexural and shear behavior of UHPCC composite beam [thesis]. Harbin: Harbin Institute of Technology(2014)

39. P. Wirojjanapirom, K.Matsumoto, K. Kono, J. Niwa, Proceeding of the International Symposium on Ultra-
High Performance Fibre-Reinforced Concrete, 187196(2013)

40. T.J. Mohammed, B.H.A. Bakar, N.M. Bunnori, Constr Build Ma, 106, 533-542(2016)

41. Issa Brown Mpalla. Uniaxial compression behavior of wire meshed UHPFRC-RC composite column[Thesis]. Harbin: Harbin Institute of Technology(2014)

42. B. Shan, Z. Liu, Y. Xiao, et al, J Hunan Univ, 44, 8896(2017). 